\title{
O DIREITO CHINÊS E A MEDIAÇÃO: COMO O BRASIL CHEGARÁ LÁ?
}

\author{
THE CHINESE LAW AND THE MEDIATION: HOW CAN BRAZIL GETS THERE?
}

\author{
${ }^{1}$ Maria Cláudia Mércio Cachapuz \\ ${ }^{2}$ Clarissa Pereira Carello
}

\section{RESUMO}

A China produz ensinamentos em termos de solução autocompositiva de conflitos que podem influenciar o ocidente, em especial no que diz respeito a mediação de controvérsias. Sob essa influência, em 2010, inicia-se um movimento no Brasil, através da edição da Resolução 125 do Conselho Nacional de Justiça (CNJ) que traz a mediação como política pública e como um instrumento possível para aplicação no Poder Judiciário. Desde então, uma lei especifica foi editada, assim como a mediação passou a constar no novo Código de Processo Civil. Por isso a indagação: Será que o Brasil está preparado para essa mudança de paradigma?

Palavras-chave: Direito comparado, Mediação, Métodos autocompositivos

\begin{abstract}
China produces knowledge from the point of view of auto-compositive conflict resolution that so far influences other countries. Under this influence, in 2010, began a movement in Brazil, through the issuance of Resolution 125 of the National Council of Justice that brings mediation as a public policy and as a possible tool for application in the judiciary sistem. Since then, a specific law was enacted, as well as mediation was entered in the new Civil Procedure Code. However, the question remains: Is Brazil prepared for this paradigm shift?
\end{abstract}

Keywords: Comparative law, Mediation, Auto-compositive methods

\footnotetext{
${ }^{1}$ Pós-Doutorado em Direito pelo Centro Universitário Ritter dos Reis - UniRITTER, Porto Alegre, Rio Grande do Sul, (Brasil). Professora da Graduação (Parte Geral de Direito Civil, Teoria Geral dos Contratos, Responsabilidade Civil)da Universidade Federal do Rio Grande do Sul - UFRGS. E-mail: mcmcachapuz@tj.rs.gov.br

${ }^{2}$ Especialização em Direito Empresarial pela Pontifícia Universidade Católica - PUC, Porto Alegre, Rio Grande do Sul, (Brasil). Professora do Centro Universitário Ritter dos Reis - Uniritter, nos Cursos de Ciências Jurídicas e Sociais, Ciências Contábeis e Administração de Empresas. E-mail: clarissacarello@ hotmail.com
} 


\section{INTRODUÇÃO}

O tema da mediação, embora há algum tempo trabalhado academicamente na doutrina jurídica brasileira, é bastante recente em relação a uma adoção jurisdicional fato ocorrido apenas quando da edição do Código de Processo Civil de 2015. Por isso a suscitação de questionamentos diversos quanto à implementação no âmbito do processo de conhecimento judicial - a chamada hipótese de "mediação intrajurisdicional" (REGLA, 2015, p. 97) -, seja pela aparente dificuldade de construção de um discurso afinado à cultura do litígio jurisdicional, seja porque reconhecida certa insuficiência de formação dos operadores jurídicos para lidarem com esta forma de composição em situações de conflito.

De certa forma, a ideia de se trazer a mediação para dentro de um processo de conhecimento de demandas judiciais permite que se identifique não tanto a necessidade de gerir-se de forma satisfatória o número de processos que aguardam uma determinada resposta jurídica - o que, de fato, traduz-se como um efeito possível pela forma alternativa de composição de conflitos -, mas principalmente a alteração de enfoque quanto à perspectiva de enfrentamento excessivamente burocrático ou de "excessiva rigidez" (REGLA, 2015, p. 97) conferida à resolução de conflitos que chegam ao Poder Judiciário. A questão é que se partindo de pressupostos tão distintos em termos argumentativos, falarse de uma associação entre mediação e processo judicial remete a certa dificuldade metodológica - e mesmo filosófica - de compreender-se a possibilidade de se desenvolver, paralelamente, linguagens distintas de busca de soluções pelo enfrentamento de conflitos com reflexos judiciais.

Daí a preocupação de se trabalhar, em perspectiva comparada, com culturas jurídicas igualmente distintas à brasileira, de forma a se buscar subsídios necessários e, possivelmente, capazes de trabalhar com enfoques distintos sobre os métodos de (auto) composição de litígios - para a compreensão de procedimentos recentemente adotados e que passam a integrar o trabalho contemporâneo das cortes de julgamento. A relevância do estudo comparativista reside, justamente, na preocupação de melhor compreender-se a realidade nova, na perspectiva de alcançar-se a efetivação prática dos direitos em sociedade. 
Tratando-se de discussão, portanto, quanto a um método de autocomposição de demandas, a opção, neste trabalho de pesquisa, centra-se na análise de métodos de resolução de conflitos junto a culturas bastante distintas que incorporam, em sua estrutura de constituição, técnicas de enfrentamento de conflitos por perspectivas não apenas jurídicas, mas compartilhadas pela própria tradição cultural de determinada sociedade. Assim, na opção de estudo pela cultura chinesa, em que a regulação por meio de leis afasta-se dos ensinamentos do filósofo Confúcio (séc. V A.C.). Para os chineses, cabe a cada individuo responsabilizar-se pela solução de seus conflitos através de uma concepção moral extrajurídica e não baseada apenas na legalidade. É a ética social que influencia o cotidiano, cabendo a cada um a resolução de seus conflitos. Algo, na essência, um pouco diverso do que ocorre no Brasil, em que mesmo as hipóteses de mediação operam pelo intermédio de uma terceira pessoa, a quem se confia autoridade para a condução de um processo de conhecimento amplo.

Há, contudo, perspectivas de mudança. Primeiramente, por meio da publicação da Resolução 125 do Conselho Nacional de Justiça (CNJ), em 29 de novembro de 2010. Posteriormente, pela publicação da Lei Federal n ${ }^{\circ} 13.140 / 15^{1}$, conhecida como "Marco legal da mediação", e, por fim, pela implementação do novo Código de Processo Civil (Lei Federal $\left.n^{\circ} 13.105 / 15\right)$, em que conferido destaque relevante para o tema da mediação. O objetivo do presente artigo, portanto, é, em perspectiva comparada, buscar nas raízes da cultura chinesa e no seu enfoque paralegal aspectos suficientes que possam influenciar o intérprete brasileiro na adequada e correta composição dos conflitos que apresentem reflexos também na seara jurídica.

\section{O EXEMPLO DO DIREITO CHINÊS}

Inicialmente, para se compreender a ordem social associada às tradições chinesas, deve se conhecer os dados históricos daquele País, que viveu livre de influências estrangeiras - e, fundamentalmente, de uma colonização por tradições ocidentais - até o século XIX. Tal compreensão parte, independentemente de uma interpretação teleológica, de uma aproximação filosófica das tradições culturais da

\footnotetext{
${ }^{1}$ http://www.planalto.gov.br/ccivil_03/_Ato2015-2018/2015/Lei/L13140.htm. Acesso em 15 dez 2015.
} 
sociedade chinesa, fundadas numa interação naturalística entre o céu, a terra e os homens. Em termos filosóficos, a busca por uma resposta naturalística - muito próxima à ideia de um direito natural conhecido da tradição ocidental clássica - permitiu a identificação de uma ordem cósmica, capaz de reger os fenômenos naturais e de distinguir, tais regras invariáveis, das regras estabelecidas pelos homens, livres por sua condição de seres autônomos e, nessa medida, responsáveis pela ordem ou pela desordem do mundo (DAVID, 1998).

Na tradição chinesa, a harmonia entre o homem e a natureza e entre os semelhantes é o que viabiliza a felicidade. Para que essa harmonia entre os homens aconteça, a ideia de conciliação e consenso é que deve prevalecer. O litígio, as decisões por maioria, ou mesmo ideias de autoridade e de coerção afastam a liberdade de entendimento que deve prevalecer nas relações. Persuasão e propostas validadas pelos sujeitos envolvidos no processo jurídico conduzem o Direito a uma denominada "função menor". O ideal é de que os indivíduos possam usufruir de uma plena autonomia na tomada de suas decisões, sem que necessitem submeter a terceiros o que lhe é confiado (DAVID, 1998).

Quando, de certa forma, afasta-se da sociedade o controle da legislação escrita, os costumes acabam por exercer um importante papel na disciplina da conduta correta a ser adotada pelos sujeitos. Conforme o destaque de Wolkmer,

"Toda a cultura tem um aspecto normativo, cabendo-lhe delimitar a
existencialidade de padrões, regras e valores que institucionalizam os
modelos de conduta. Cada sociedade esforça-se para assegurar uma
determinada ordem social, instrumentalizando normas de
regulamentação essenciais, capazes de atuar como sistema eficaz
de controle social. Constata-se que, na maioria das sociedades
remotas, a lei é considerada parte nuclear do controle social,
elemento material para prevenir, remediar ou castigar os desvios
das regras prescritas. A lei expressa a presença de um direito
ordenado na tradição e nas práticas costumeiras que mantêm a
coesão do grupo social." (WOLKMER, 2012)

Por ter em suas origens os preceitos sobreditos, os ritos acolhidos pelos costumes demonstram as influências do confucionismo na China. No mesmo sentido, a família, a partir de um núcleo cultural de menor abrangência, traduz-se como a base 
organizada para que o "chefe" do clã adote as medidas cabíveis para guiar as decisões de seus membros, evitando decisões arbitrárias. Numa espécie de aproximação complementar da Moral e do Direito, são os preceitos morais chineses que devem guiar, num primeiro momento, as decisões. Uma conduta de prevenção deve ser adotada antes de qualquer intuito de punição; a explicação deveria vir antes de uma ordem e, assim, sucessivamente. A sociedade organizada dessa forma permite que a sociedade chinesa viva, historicamente, sem a necessidade de desenvolver ritos jurídicos específicos, inclusive para o exercício de tarefas profissionais típicas de aplicadores do Direito. Daí porque consta no histórico de desenvolvimento da atividade profissional de advogados, denominados como "homens da lei", o fato de costumarem ser consultados em encontros sigilosos, porque desenvolveriam uma atividade considerada menor ou tendente a regular relações entre aqueles com incapacidade de pleno exercício de uma autonomia. (DAVID, 1998). Ainda sob essa perspectiva, o Direito não é excluído da sociedade, mas considerado "bom para os bárbaros" (DAVID, 1998), valendo para aqueles que não têm preocupações com a moral e a sociedade. Trata-se ainda de uma disciplina de conduta aplicável aos estrangeiros que não componham a civilização chinesa e que, portanto, não compreendem os preceitos morais que influenciam as tomadas de decisões (DAVID, 1998).

Mesmo com o passar do tempo e a assunção de diferentes dinastias, o modo de solução de conflitos segue a influência do confucionismo, garantindo aos chineses outros meios de busca à justiça, influenciando-se basicamente pelos costumes. Sob o ponto de vista histórico-político, vale consignar que nem mesmo a China comunista deixou-se influenciar pelo princípio da legalidade, mesmo que identificadas situações severas de restrições a liberdades individuais. As bases da sociedade permaneceram sendo a educação cívica da população e o investimento na formação moral, mesmo que passível de crítica os objetivos políticos pretendidos com a formação de determinados regimes políticos em concreto. Se há uma aproximação hoje com a estruturação do sistema jurídico chinês a uma realidade mais ocidental, esta ocorre, essencialmente, por uma necessidade específica de manutenção de efetivas relações econômicas com os países de base ocidental.

Relativamente à mediação, é possível afirmar que esta tem, em grande medida, suas raízes no direito chinês. É por meio do estimulo ao diálogo entre os participantes de um processo de conhecimento pela mediação que a gestão dos conflitos é viabilizada. 
Primeiramente, a figura do mediador corresponderia ao chefe da família, responsável por auxiliar os envolvidos no conflito para o alcance de um consenso. A oralidade e a intuição são elementos presentes nesse exercício de consenso que acabaram sendo transmitidos entre as gerações (FAGÚNDEZ, 2014).Vale dizer que, atualmente, no território chinês, existem mais de duzentas mil comissões populares de mediação, o que reflete a influência dos preceitos do passado ainda nos dias atuais, mesmo que evidenciada possível situação política e ideológica distinta. Essa ampla utilização do método autocompositivo permite que se compreenda que a prática do diálogo em todos os âmbitos - seja na esfera profissional, seja na esfera mais privada (pessoal, educacional ou familiar) -, encontra-se inserida no cotidiano como forma de prevenção e gestão de conflitos. Algo que, para a compreensão chinesa, não representam um problemas, e sim, algo que faz parte “da vida” (FAGÚNDEZ, 2014).

É possível ainda que se reconheça na forma de gestão de controvérsias no território chinês também influências taoistas, na medida em que fundada na compreensão de que a vida de relação é composta por situações de perdas e de ganhos, a partir da identificação de situações de opostos em sociedade. A moral e a lei (LI e FA, respectivamente) demonstram a polarização do pensamento. Segundo anota Fagundéz:

\begin{abstract}
"Para os taoistas, nada é absolutamente yin ou yang. De acordo com a filosofia taoista, tudo no universo é yin ou yang, sendo que um se transmuta em outro permanentemente. Yin está contido em yang e yang faz parte do yin, Um elemento não existe sem o outro. A ideia de complementaridade dos interesses em jogo está sempre presente" (FAGUNDÉZ, 2014)
\end{abstract}

$\mathrm{Na}$ atualidade, o investimento chinês na formação de profissionais da área da advocacia está muito mais permeado por questões de mercado internacional e pelos reflexos da globalização na economia daquele país que qualquer outra pretensão de desenvolvimento de uma estrutura autônoma de um sistema de solução de conflitos. E isto, de certa forma, pode ser extremamente perigoso. A ausência de uma estrutura jurídica suficiente à estimulação litigiosa de conflitos permite, numa outra medida, evitar-se o próprio acesso à realização de justiça pela reclamação possível a todo o cidadão - o que, por um lado, inibe o teste crítico quanto ao exercício de direitos gerais de liberdade e igualdade por todos em sociedade. 
Aqui, contudo, o enfoque que se oferece é quanto à parcela positiva desta ausência de estrutura a partir de uma tradição cultural genuína da sociedade chinesa em termos de consenso, e não a situação político-ideológica capaz de ser extraída das dificuldades de acesso à justiça formal. Por isso o destaque que é oferecido ao que se encontra na doutrina especializada, como segue:

"Com grande paciência, procura-se levar os cidadãos a reconhecerem os seus erros e a corrigirem-se, quer se trata de questões civis ou penais. Aquele que incorrer em erro não é conduzido até os juízes: as próprias pessoas de seu meio, discutindo com ele e manifestando a sua reprovação, reconduzem- no ao bom caminho. Os processos são raros; eles apenas intervêm contra os inimigos do povo, os incorrigíveis e os depravados. (...) O direito é o último remédio para os casos em que os outros modos de solução dos litígios tenham excepcionalmente falhado." (DAVID, 1998)

Por meio desse panorama histórico é possível compreender-se, em certa medida, as motivações da cultura chinesa para a conferência de uma força interpretativa bastante específica à cultura da mediação e, fundamentalmente, a partir de uma preocupação com a ideia de consenso e de autonomia resolutiva aos indivíduos. Para os chineses não é oportuno - e pouco aceito, em verdade - que um terceiro passe a interferir e condicionar a resolução de um conflito de forma externa. Resolver suas próprias questões faz parte do cotidiano chinês - uma tarefa necessária -, competindo a cada indivíduo demonstrar a capacidade e a habilidade suficientes para a harmonização das situações de conflito verificadas em sociedade.

\section{O DIREITO BRASILEIRO E AS PERSPECTIVAS DA MEDIAÇÃO}

A Constituição Federal de 1988 procurou ampliar o acesso à justiça, especialmente pelas normas dispostas no art. $5^{\circ}$, inc. $\mathrm{XXXV}^{2}$. No mesmo sentido, houve significativas inovações legais para viabilizar o acesso ao Poder Judiciário a um maior

\footnotetext{
${ }^{2}$ Art. $5^{\circ}$ Todos são iguais perante a lei, sem distinção de qualquer natureza, garantindo-se aos brasileiros e aos estrangeiros residentes no País a inviolabilidade do direito à vida, à liberdade, à igualdade, à segurança e à propriedade, nos termos seguintes:

XXXV - a lei não excluirá da apreciação do Poder Judiciário lesão ou ameaça a direito;
} 
número de pessoas (SARLET, 2009). Nesse sentido, o intuito de edição da Lei dos Juizados Especiais (Lei Federal n 9099/95), que permite o acesso dos indivíduos, por composição, à resolução de seus conflitos mesmo quando desamparados da assistência por advogados. Circunstância que abrange tanto a propositura de demandas, como o próprio comparecimento em audiência e realização de contestação e instrução do processo.

Tais garantias de acesso à justiça acabaram por abarrotar o Poder Judiciário de demandas repetitivas - e outras tantas singulares - que tramitam pelas dependências cartorárias sem uma efetiva solução por um período razoável de tempo. Nesse cenário, em 2010, surge a primeira regulamentação do instituto da mediação judicial no Brasil. Por meio da publicação da Resolução $n^{\circ} 125$ do Conselho Nacional de Justiça $(\mathrm{CNJ})^{3}$, em novembro daquele ano, passa-se a viabilizar a resolução de conflitos através de métodos autocompositivos, difundindo o papel da mediação e a forma como os Centros de Soluções de Conflitos deveriam ser instituídos dentro da estrutura do Poder Judiciário. Pouco a pouco, o movimento em prol da composição dos litígios ganha força e, como política pública que é desde sua concepção, espalha-se nos Estados da Federação. Em menos de cinco anos, duas leis são publicadas na sequência. A primeira delas é a Lei Federal $n^{\circ} 13.105 / 15$, que dá nova redação ao Código de Processo Civil, encampando, no procedimento judicial, o rito da mediação; a segunda, conhecida como "Marco Legal da Mediação" - Lei Federal n ${ }^{\circ}$ 13.140/15 - apresenta uma descrição detalhada do papel dos mediadores judiciais e extrajudiciais, estabelecendo ainda os princípios e os procedimentos aplicáveis ao método de autocomposição de conflitos.

A partir da edição da Resolução do CNJ, percebe-se a inserção da autocomposição na sociedade brasileira, marcando-se a possibilidade de resolução de conflitos inclusive de forma pré-processual. Essas medidas são viáveis através da capacitação de servidores do Poder Judiciário e de mediadores para que atuem como facilitadores do diálogo daqueles envolvidos no conflito encaminhado à seara jurídica (SQUADRI, 2015). Oportuno esclarecer que podem ser mediadores profissionais de múltiplas especialidades, e não apenas técnicos da área jurídica. Todavia, o mediador deverá ter técnica para negociação cooperativa e auxiliar na comunicação, com conhecimentos de linguística e semiótica. Impõe ainda ter conhecimento suficiente na

${ }^{3}$ BRASIL. CNJ. Resolução no 125 do Conselho Nacional de Justiça. DP: 01 dez. 2010. Disponível em: http://www.cnj.jus.br///images/atos_normativos/resolucao/resolucao_125_29112010_16092014165812.p df. Acesso em: 15 dez. 2015. 
área de Psicologia, para tratamento das questões mais sensíveis apresentadas na sessão de mediação, de forma a desenvolver capacitação suficiente para realizar a gestão de conflitos e observar os aspectos sociológicos (VEZZULLA, 1999).

No mesmo sentido, a mediação não terá caráter impositivo, pela disciplina no novo Código de Processo Civil, pois se assim fosse, estaria desvirtuado o propósito da autocomposição. Para que se atinja o objetivo dessa política publica, é necessário que ambas as partes - mediandos, na perspectiva do novo instituto - estejam de acordo com a realização da sessão, pois é uma forma voluntária para viabilizar a resolução dos conflitos (CAHALI, 2011). Oportuno referir que a mediação brasileira sofreu fortes influências do instituto argentino, que igualmente é inspirado no modelo de Harvard, onde o foco para a solução do conflito está na negociação advinda do estimulo do diálogo entre as partes (TARTUCE, 2015).

Durante a sessão de mediação, o método utilizado pelos intérpretes deverá estimular o diálogo entre os mediandos, pois estes devem ser os protagonistas naquele ato. A presença do advogado é facultativa, pois a ideia é que seja trabalhada a autonomia dos indivíduos que estão em litígio e não a melhor técnica ou argumentação jurídica. Por haver confidencialidade do que é falado pelos mediando ao longo da sessão, não há produção de provas ou juntada de documentos neste ato. A fala e a escuta alternadas, a voluntariedade e a consciência de que a cultura "ganha-perde" não seja a melhor alternativa, viabilizam o entendimento entre as partes, que poderão solucionar ou transformar seus conflitos interpessoais (VASCONCELOS, 2014).

O objetivo da mediação, portanto, é afastar das pessoas a pré-compreensão de que cabe apenas ao Estado interpretar e declarar o direito aplicado ao caso, pressupondo-se a possibilidade de cada um, de forma autônoma, alcance a solução ao conflito. Sob essa ótica, a mediação passa a ser vista como um a ferramenta processual relevante igualmente numa seara intersubjetiva.

"Para falar de mediação é preciso introduzir uma teoria do conflito mais psicológica que jurídica. No momento que os juristas falam de conflito, o reduzem à figura do litígio, o que não é o mesmo. Quando se decide judicialmente, por meio de um litígio se consideram normativamente os efeitos; deste modo, o conflito pode ficar cristalizado, retornando agravado em qualquer momento futuro. Os juristas quando intervém em um conflito, apelam ao 
imaginário jurídico, que eu denomino de sentido comum teórico do Direito. (WARAT, 2001)

Há, a partir de tal compreensão, a possibilidade de que também o conflito, em termos subjetivos, contribua para um crescimento individual, com reflexos mais permanentes à construção de vínculos sociais.

Os juristas nunca pensam o conflito em termos de insatisfação emocional ou de sentimento. Falta no Direito uma teoria do conflito, que nos mostre como o conflito pode ser entendido como uma forma de produção, com o outro (...). O conflito como uma forma de inclusão do outro na produção do novo: o conflito como autoridade que permite administrar com o outro (diferente) para produzir a diferença. (WARAT, 2001)

Essa alteração na forma de compreensão do alcance do fenômeno jurídico, por meio da regulamentação da mediação no Brasil, demonstra a necessidade de se repensar às demandas levadas ao Poder Judiciário, que não consegue dar efetividade a todo o seu contingente processual.

\begin{abstract}
“Assinala-se que a crise que se abate sobre o arcabouço jurídico tradicional está perfeitamente em sintonia com o esgotamento e as mudanças que atravessam os modelos vigentes nas ciências humanas. Adverte-se que as verdades metafísicas e racionais que sustentaram durante séculos as formas de saber e de racionalidade dominantes, não mais mediatizam as inquietações e as necessidades do presente estágio da modernidade liberal-burguês-capitalista. [...] abrindo espaço para se repensar padrões alternativos de referência e legitimação.” (WOLKMER, 2015)
\end{abstract}

E isto, de certa forma, atenderia ao aspecto igualmente subjetivo a envolver a ideia de autonomia da vontade, permitindo ao indivíduo reconhecer no exercício de uma liberdade a dinâmica intersubjetiva que deve ser pressuposta. Evitaria, como destaca Francisco Amaral dos Santos Neto, que acabasse por se compreender a autonomia apenas por um determinada ótica de enfrentamento. 


\begin{abstract}
"Por muitos considerado como sinônimo de autonomia da vontade, com ela, a meu ver, não se confunde, pois a expressão "autonomia da vontade" tem uma conotação subjetiva, psicológica, enquanto "autonomia privada" significa o poder particular de criar relações jurídicas de que se participa. Assim, é o poder que nós, particulares, temos, de regular juridicamente as nossas relações, dando-lhes conteúdo e eficácia juridicamente reconhecidos." (SANTOS NETO, 2006)
\end{abstract}

O desafio, portanto, reside em buscar não se descaracterizar o procedimento de mediação no decorrer do tempo, principalmente pelo desconhecimento técnico que envolve o método proposto. Ainda mais em países, como o Brasil, em que tímida e lenta é a implementação do sistema em meio a uma cultura de litígio bastante acentuada.

\title{
4. A MEDIAÇÃO NORMATIVA: O QUE O BRASIL DEVE APRENDER COM A EXPERIÊNCIA CHINESA
}

Uma das questões que se traduzem como relevantes ao tratar-se do tema da mediação é saber se, com base em critérios de autonomia, será possível reconhecer-se efetiva implementação do instituto no ordenamento jurídico brasileiro. Será possível incutir na mentalidade de litígio dos indivíduos de que existe, mesmo no âmbito judiciário, um espaço próprio ao ato de tomar decisões de forma suficiente para, com autonomia, resolver os próprios problemas? E, em que medida tal exercício efetivamente será produto de uma autocomposição por meio do método de composição pela mediação?

Sob o prisma do direito chinês, como antes referido, verifica-se que o ponto de base para o êxito nas composições obtidas pela mediação pode ser atribuído aos ensinamentos transmitidos entre gerações, reconhecendo-se um papel central a ética desenvolvida como pauta ao relacionamento intersubjetivo. Naquela cultura, ao contrário do estimulado pelo ordenamento jurídico brasileiro, ter que recorrer ao direito 
positivo denota o "desmoronamento da ordem social e de uma falta de harmonia entre o Estado e a sociedade" (ARNAUD, 1999).

No Brasil, o destaque judicial é conferido aos personagens que atuam como intérpretes - do juiz aos advogados - e a quem se confere, em certa medida, o direito e o dever de se manifestarem em nome dos atingidos pela solução do conflito - aqueles denominados como partes. Como aponta Arnaud, na China, os conflitos que demandam mediação são personificados e contextualizados por relações sociais estabelecidas e expressas pelos próprios destinatários das soluções que se farão alcançadas em concreto. A ideia de um julgamento por terceiros é, de certa forma, afastada, sendo relevante ao indivíduo que desenvolva suficiente aptidão para, por si mesmo, solucionar as demandas postas e restabelecer relações de convívio (ARNAUD, 1999).

Daí a preocupação da sistematização dos números que envolvem o problema da litigiosidade no direito brasileiro, como expresso pelo Conselho Nacional de Justiça $(\mathrm{CNJ})$, de forma a refletir a realidade de julgamentos no Brasil no ano de $2014^{4}$.

\section{Desempenho por instâncias - 2014}

Casos novos Julgados Pendentes $\quad$ Em tramitação

$1^{\circ} \mathrm{Grau}$ - $\quad 17.040 .148 \quad 15.406 .636 \quad 29.815 .011 \quad 46.855 .159$

Conhecimento
$1^{\circ} \mathrm{Grau}-$
6.649 .499
6.134 .957
35.936 .314
42.585 .813

Execução

$\begin{array}{ccccc}1^{\circ} \mathrm{Grau} \text { - total } & 23.689 .647 & 21.541 .593 & 65.751 .325 & 89.440 .972 \\ 2^{\circ} \mathrm{Grau} & 3.539 .636 & 3.763 .166 & 3.037 .255 & 6.576 .891 \\ \text { Turmas } & 1.066 .565 & 990.729 & 1.413 .448 & 2.480 .013\end{array}$

Recursais

$\begin{array}{llll}\text { TRU } & 3.971 & 2.920 & 2.551\end{array}$

\footnotetext{
${ }^{4}$ CARDOSO, Maurício. Brasil atinge a marca de 100 milhões de processos em tramitação na justiça. Disponível em: http://www.conjur.com.br/2015-set-15/brasil-atinge-marca-100-milhoes-processos$\underline{\text { tramitacao. }}$ Acesso em 13 dez. 2015
} 


\section{Desempenho por instâncias - 2014}
Tribunais
578.844
691.964
624.008
1.202 .852

Superiores

(sem STF)

Total

28.878 .663

26.990 .372

70.828 .587

99.707.250

Percebe-se que dos quase cem milhões de processos existentes a época do levantamento, quase oitenta por cento se concentra no primeiro grau de jurisdição, seja em fase de conhecimento ou em fase executiva. Justamente pelos números acima, percebe-se o perfil litigante da população brasileira e a advertência de que algo deve ser proposto para solucionar esses conflitos, sob pena de inviabilizar-se a análise dos processos judiciais considerando o número de magistrados e servidores por cidadão.

Por certo, não será a simples reforma da lei processual ou do sistema judiciário que irão auxiliar a uma diminuição desses números. Aliás, as reformas no Poder Judiciário não se traduzem como situações de novidade no histórico do país. Ainda em 1832 e em 1841 foram realizadas alterações em relação ao papel desempenhado pelo juiz como intérprete e, em 1871, suas atribuições foram ampliadas, mediante a adoção do rito sumaríssimo, com características para o oferecimento de um procedimento de julgamento mais simplificado e sem tantas formalidades (WOLKMER, 2015). O mesmo se verifica em relação à adoção de ritos simplificados em termos de composição, como pela adoção de solução dos litígios por meio do rito dos Juizados Especiais, ainda que fundada a solução compositiva pela interferência de terceiro no processo de resolução dos litígios.

A mediação surge no contexto processual como uma ferramenta de resgate de autonomia para os indivíduos envolvidos em uma demanda judicial, descabendo que seja confundida como mais uma possibilidade de descongestionamento do Poder Judiciário. A crítica, no entanto, que pode ser efetuada refere-se ao fato de que, no Brasil, foi necessária a edição de uma lei para que restasse viabilizado o diálogo entre os indivíduos. Ou seja, acaba por se reconhecer que, para que haja consciência quanto à possibilidade de resolução de um determinado conflito e em face da demora à resolução de litígios pela via judiciária, torne-se necessário o prévio ingresso judicial com uma 
demanda, levando-se para o rito processual uma forma de composição que trabalhe com a própria autonomia dos indivíduos para a resolução dos conflitos - e não apenas com um intuito de conciliação para o caso, mas com a pretensão de tornar efetivamente definitiva a situação de discussão que conduz a uma solução para o conflito.

Diante desse panorama, relevante é identificar-se, assim como em Hannah Arendt (1959), a necessidade de que haja contextualização dos problemas em sociedade, de forma que não haja mera intervenção do Estado no âmbito da esfera social, mas que esteja a própria sociedade preparada para acolher as mudanças de enfoque que se fazem necessárias para o convívio social de forma equilibrada.

"Em nenhuma circunstância exporia meu filho a condições que dariam a impressão de querer forçar a sua entrada nem grupo em que não é desejado. Psicologicamente, a situação de não ser desejado (uma situação embaraçosa tipicamente social) é mais difícil de suportar do que a franca perseguição (uma situação política embaraçosa) porque o orgulho pessoal está envolvido. (...) Além do mais, se fosse negra, sentiria que a própria tentativa de começar a dessegregação na educação e nas escolas não tinha apenas deslocado, e muito injustamente, a carga de responsabilidade dos ombros dos adultos para os das crianças. Estaria também convencida de que há em todo o empreendimento uma implicação de tentar evitar a questão real." (ARENDT, 1959)

Trazendo a questão para o procedimento de mediação, o que se poderia indagar é quanto à efetiva necessidade de acolher-se a mediação dentro do rito processual judiciário, como se o ato o banalizasse de certa forma pela própria concepção de litigiosidade inerente à lide que é proposta. Será que o autor, que declara em sua petição inicial ter efetivo interesse na realização de um processo de mediação e oferece, desde logo, os pressupostos para um discurso litigioso, não acaba por justamente acirrar os ânimos de disputa numa lide? Se esta for uma hipótese viável, de fato, pode se estar, pela nova legislação, afastando-se das características que importam em termos compositivos, justamente porque não desafiada a situação de autonomia que pretende se estimular por meio da mediação.

O desafio, sem dúvida, será, para futuro, conseguir implementar a mediação a partir de técnicas cognitivas suficientes à condução de negociações entre os indivíduos, 
permitindo que tenham estes o papel central na tomada de decisão. E isto sem que se despreze o papel igualmente relevante dos demais intérpretes jurídicos, no que contribuirá o papel desenvolvido pelo próprio mediador. Algo que demandará tempo de trabalho, educação distinta em termos de formação de demandas e disposição ampla, de todos os participantes, a uma abertura ao diálogo e à compreensão de que podem ser adotados ritos diversos à composição dos litígios. Uma alteração de mentalidade que se faz necessária de forma a reconhecer-se uma efetiva "arte da mediação" (REGLA, 2015).

\section{CONSIDERAÇÕES FINAIS}

O presente artigo buscou demonstrar que o instituto da mediação surge no cenário brasileiro como uma alternativa, judicial ou extrajudicial para viabilizar a aplicação do método autocompositivo nas questões postas em litígio. Todavia, não deve ser compreendido o instituto como algo que resgatará o papel desempenhado pelo Poder Judiciário, como se os Centros Judiciários de Solução de Conflitos (CEJUSC) fossem uma extensão dos gabinetes dos juízes, visando desafogar o excesso de trabalho que lhes assola. A Resolução $\mathrm{n}^{\circ} 125$ do $\mathrm{CNJ}$ surgiu como política pública, o que denota a intenção de difundir a sistemática da medicação, o papel desenvolvido pelos mediadores, e devolver a autonomia de escolha a população. No mesmo ponto, o direito chinês foi colacionado como fonte de inspiração e contraponto, posto que no país oriental não é necessário que uma lei venham estimular o diálogo entre as partes. Desde seus remotos registros, os chineses utilizavam a palavra, o diálogo e a exposição de suas ideias, para que fosse atingido o melhor aos envolvidos.

A crítica que se pode fazer, mesmo que de forma prematura haja vista a recente aplicação do novo Código de Processo Civil com enfoque na mediação, é que descabe que se reconheça uma desvirtuação dos fundamentos e aplicação da mediação. O receio que se tem é, justamente, quanto à falta de maturidade e de reflexão dos indivíduos para lidar com a possibilidade de resolução dos próprios conflitos, de forma que a ausência cultural de habilidades para a composição de soluções aos problemas individuais não acabe por prejudicar a efetividade do procedimento de mediação. 
De outra parte, vê-se também a dificuldade de que, por meio da normatividade, possa se impor uma mudança da cultura do litígio a toda uma sociedade. O desafio, configura-se, neste começo de implementação do novo CPC e da regulação específica do instituto da mediação, em conseguir-se implementar a mediação a partir de técnicas cognitivas suficientes à condução de negociações entre os indivíduos, de forma que tenham estes o papel central na tomada de decisões concretas. Uma circunstancia que deve envolver não apenas os que se encontrem em conflito, mas todos os demais intérpretes jurídicos que participem do processo de composição de interesses, no que contribuirá o papel desenvolvido pelo próprio mediador. Por certo, uma realidade que requererá não apenas tempo de trabalho individualizado, para cada caso, mas igualmente o desenvolvimento de educação distinta em termos de formação de relações de conflito, a fim de que todos os participantes possam estar abertos ao diálogo e à compreensão de que podem ser adotados ritos diversos à composição dos litígios.

\section{REFERÊNCIAS}

AMARAL DOS SANTOS NETO, Francisco . Autonomia Privada. Revista CJF. N. 5, artigo 5. Disponível em: ww.cjf.gov.br/revista/numero9/artigo5.htm, acesso em 21 nov. 2015

ARENDT, Hannah. Reflections on little rock. Disponível em: http://learningspaces.org/forgotten/little_rock1.pdf .Acesso em $12 \mathrm{dez} .2015$.

ARNAUD, André-Jean. Dicionário Enciclopédico de Teoria e de Sociologia do Direito. 2. ed. Rio de Janeiro: Renovar, 1999

BRASIL. Constituição (1988). Constituição da República Federativa do Brasil. Brasília, DF: $\quad$ Senado, $1988 . \quad$ Disponível em <http://www.planalto.gov.br/ccivil_03/Constituicao/Constituicao.htm>. Acesso em: 29 nov. 2015

Conselho Nacional de Justiça. Resolução ${ }^{\circ} 125$ do Conselho Nacional de Justiça. DP: 01 dez. 2010.2 Disponível em: http://www.cnj.jus.br///images/atos_normativos/resolucao/resolucao_125_29112010_16 092014165812.pdf. Acesso em: 15 dez. 2015

CAHALI, Francisco José. Curso de Arbitragem. 2. Ed. São Paulo: Revista dos Tribunais, 2011.

CARDOSO, Maurício. Brasil atinge a marca de 100 milhões de processos em tramitação na justiça. Disponível em: http://www.conjur.com.br/2015-set-15/brasilatinge-marca-100-milhoes-processos-tramitacao. Acesso em 13 dez. 2015 
DAVID, René. Os grandes sistemas do direito contemporâneo; tradução Hermínio A. Carvalho. $3^{\text {a }}$ Ed. São Paulo: Martins Fontes, 1998.

FAGUNDEZ, Paulo Roney Ávila.Reflexões sobre a história do direito chinês. In: WOLKMER, Antônio Carlos. (Org.). Fundamentos da História do Direito. 8 Ed.Belo Horizonte: Editora Del Rey, 2014.

REGLA, Josep Aguiló. EI arte de La mediación. Madrid, Trotta, 2015.

SARLET, Ingo Wolfgang. A eficácia dos direitos fundamentais: uma teoria geral dos direitos fundamentais na perspectiva constitucional. 10. ed. rev. atual. e ampl. Porto Alegre: Livraria do Advogado Ed. 2009.

SQUADRI, Ana Carolina. MUNIZ, Joaquim de Paiva; VERÇOSA, Fabiane; PANTOJA, Fernanda Medina; e ALMEIDA, Diogo de Assumpção Rezende de. (Coord). In: Arbitragem e Mediação Temas Controvertidos. Disponível em: http://webapp3.pucrs.br/bcwebapps/Redirect?app=MBB\&ISBN=978-85-309-59111.Acesso em: 14 dez. 2015.

SARLET, Ingo Wolfgang. A eficácia dos direitos fundamentais: uma teoria geral dos direitos fundamentais na perspectiva constitucional. 10. ed. rev. atual. e ampl. Porto Alegre: Livraria do Advogado Ed. 2009.

TARTUCE, Fernanda. Mediação nos conflitos civis. 2. Ed. São Paulo: Método, 2015

VASCONCELOS, Carlos Eduardo de. Resolução Adequada de Disputas (RAD): introdução e capacitação. In: Mediação de Conflitos e Práticas Restaurativas. 3. Ed. São Paulo: Método, 2014.

VEZZUlla, Juan Carlos. A mediação. O mediador. A justiça e outros conceitos. São Paulo: LTR. 1999.

WARAT, Luís Alberto. A mediação e a teoria do conflito. Scientia iuris. Londrina, v.5. 2001.

Luís Alberto. Surfando na pororoca: O ofício do mediador. Florianópolis: Fundação Boiteux, 2004, v.3.

WOLKMER, Antônio Carlos. O direito nas sociedades primitivas. In: Fundamentos da História do Direito. 7 ed. Belo Horizonte: Del Rey, 2012

2015.

. História do Direito no Brasil. $9^{\circ}$ ed. rev. e atual. Rio de Janeiro: Forense,

. Pluralismo jurídico:fundamentos de uma nova cultura no Direito. $4^{\circ}$ ed. São Paulo: Saraiva, 2015. 